\title{
MASTER
}

$$
\text { WAPD-TM-I57 }
$$

AEC RESEARCH AND

DEVELOPMENT REPORT

\section{THE SAMPLING ESTIMATE OF THE PARAMETER VARIANCE/MEAN IN REACTOR FLUCTUATION MEASUREMENTS}

August 1958

CONTRACT AT-11-1-GEN-14

BETTIS PLANT

PITTSBURGH, PENNSYLVANIA

Operated for the U.S. ATOMIC ENERGY COMMISSION bY BETTIS ATOMIC POWER DIVISION, WESTINGHOUSE ELECTRIC CORPORATION 


\section{DISCLAIMER}

This report was prepared as an account of work sponsored by an agency of the United States Government. Neither the United States Government nor any agency Thereof, nor any of their employees, makes any warranty, express or implied, or assumes any legal liability or responsibility for the accuracy, completeness, or usefulness of any information, apparatus, product, or process disclosed, or represents that its use would not infringe privately owned rights. Reference herein to any specific commercial product, process, or service by trade name, trademark, manufacturer, or otherwise does not necessarily constitute or imply its endorsement, recommendation, or favoring by the United States Government or any agency thereof. The views and opinions of authors expressed herein do not necessarily state or reflect those of the United States Government or any agency thereof. 


\section{DISCLAIMER}

Portions of this document may be illegible in electronic image products. Images are produced from the best available original document. 


\section{LEGAL NOTICE}

This report was prepared as an account of Government sponsored work. Neither the United States Navy, nor the Commission, nor any person acting on behalf of these agencies:

A. Makes ány warranty or representation, express or implied, with respect to the accuracy, completeness, or usefulness of the information contained in this report, or that the use of any information, apparatus, method, or process disclosed in this report may not infringe privately owned rights; or

B. Assumes any liabilities with respect to the use-of,- or for damages resulting from the use of any information, apparatus, method, or process disclosed in this report.

As used in the above, "person acting on behalf of the Commission or the U. S. Navy" includes any employee or contractor of these agencies to the extent that such employee or contractor prepares, handles or distributes, or provides access to, any information pursuant to his employment or contract with the Commission or the U. S. Navy. 
(UC-34, Physics and Mathematics TID-4500, 14th Edition)

THE SAMPLING ESTIMATE OF THE PARAMETER VARIANCE/MEAN

IN REACTOR FLUCTUATION MEASUREMENTS.

by

D. R。 Harris

August 1958

Contract AT-1I-1-GEN-14

NOTE

This document is an interim memorandum prepared primarily for internal reference and does not represent a final expression of the opinion of Westingnouse. When this. memorandum is distributed externally, it is with the express understanding that. Westinghouse makes no representation as to completeness, accuracy, or usability of information contained therein.

Printed in U.S.A. Price 75 cents. Available from the office of Technical Services, U... S. Department of Commerce, Washington 25, D. C。

Operated for the U.S. Atomic Energy Commission by Westinghouse Electric Corporation 
UC-34,..Physics and Mathematics, TID-4500, 14th Edition

SPECIAL EXTERNAL DISTRIBUTION

Manager,...Pittsburgh Naval Reactors Operations Office,

U. S. Atomic Energy Commission

John Orndoff, Los Alamos Scientific Laboratory

INTERNAL DISTRIBUTION

H. Amster

J. C。 Andrews

$R_{\text {o... T ... Bayard }}$

J .. R. Brown

H. K. Browning

J.. C. Conner

R. C. Cunningham

J. A. De Juren

W...H. Esselman

J ... R. Feldmeier

F. S. Frantz

J. N o. Grace

S. B... Gunst

D. R. Harris (25)

E. H...Hill

A. F。 Henry

L. D. Herwig

R. T. Jones

Do Klein.

S. Krasik

S. H. Levine

H. A. Morewitz
B. H. Mount

E. J. Ney

B. H. Noordhoff

J. C. Rengel

K. W. Schwanekamp

K. Shure

J. W. Simpson

G. G. Sinth

D. C. Spencer

A. Squire

S. Stein

J.T. Stiefel

R. W. Stöoksberry

J。 J. Taylor

W. Vogelsang

J. J. Volpe

P. H. Wackman

T. J. Walker

W. F. Witzig

O. J. Woodruff

library (5)

NTF Library 


\section{TABLE OF CONTENTS}

\section{Page}

ABSTRACT ......................... v v

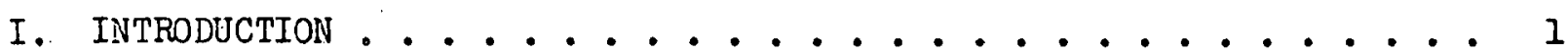

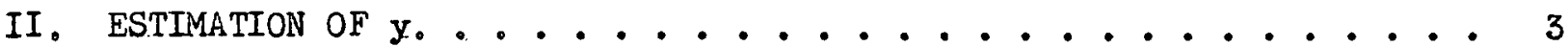

A. Large. Samples Drawn from a Non-Drifting Population . . . . . 3

B. Samples Drawn from a Population With Large Mean. . . . . . 4

C. The Usual Case ..................... 5

D... Summary........................ 7

III. TESTS OF ESTIMATION OF y BY Y. . . . . . . . . . . . . . . 7

IV. CONCLUSIONS. . . . . . . . . . . . . . . . . . 11 REFERENCES . . . . . . . . . . . . . . . . . 13 


\section{LIST OF FIGURES}

Page

F1gure . 1. Frequency. $f_{c}$ of Occurrence of C Counts in Each of 1000

Time-Intervals .................... 14

Figure 2... Frequency of Occurrence of $1+Y$ Values Calculated for

470. Blocks Each Containing Ten Time-Intervals. . . . . . 15

Figure 3.... Frequency of Occurrence of C Counts in Each of 400

Time-Intervals . . . . . . . . ..... . . 16

Figure 4. Frequency of Occurrence of $1+Y$ Values Calculated for

190 Blocks Each Containing Ten Time-Intervals. . . . . . 17 


\begin{abstract}
Reactor properties can be investigated by observing. fluctuations in the number of counts occurring in a fixed time-interval in a neutron counter. The statistical parameter variance/mean of the count population may be estimated from the observed statistic $N[N-1]^{-1} \times$ variance/mean calculated for a sample of counts obtained in $N$ time-intervals. It is shown that this method of estimation is biased, and a bound is derived for the magnitude of the bias.... The bias can be severe when $\mathrm{N}$ is small and the mean number of counts per time interval is also small. The expected distribution of the sample statistic $N[N-1]^{-1} \mathbf{x}$ variance/mean is described. The results of the study are illustrated by analysis of actual reactor fluctuation data.
\end{abstract}




\section{INTRODUCTION}

Reactor properties have been investigated by observing fluctuations in the number of counts, $C$, occurring in a fixed time-interval in a neutron counter within or near the reactor。 $(1)$ The experimental data consist of a set of frequencies, $f_{c}$, with which a particular value of $c(=0,1,2, \ldots \ldots)$ appears in $\mathrm{N}$ successive, equal time-intervals. The data are to be compared with a theoretical set, $P_{c}$, where $P_{c}$ is the probability that $C$ counts occur in a particular time-interval. The comparison of experiment and theory is facilitated by comparing moments $a_{r}, \mu_{r}$ and $a_{r}, m_{r}$ of the theoretical distriiution and measured sample, respectively. Such moments are defined. by:

$$
\begin{array}{ll}
\alpha_{r} \equiv \sum_{c=0}^{\infty} P_{c} c^{r} & a_{r} \equiv N^{-1} \sum_{c=0}^{\infty} f_{c} c^{r} \\
\mu_{r} \equiv \sum_{c=0}^{\infty} P_{c}\left(c-a_{1}\right)^{r} & m_{r} \equiv N^{-1} \cdot \sum_{c=0}^{\infty} f_{c}\left(c-a_{1}\right)^{r}
\end{array}
$$

In. particular, it has been suggested that the statistical parameter $\mathrm{y}$, defined as $\mu_{2} / a_{1}-1$, is a fixed function of interesting reactor properties when a steady average nieutron level is maintained by a neutron source in a subcritical reactor: $(\underline{2})$. The sample statistic $Y$, defined $2: \mathrm{Nm}_{2} /(\mathrm{N}-1) a_{1}-1$, has been . proposed as an experimental estimate of $\mathrm{y}_{0}(\underline{1})$

Examples show that the expected value of $Y, E(Y)$, in simple random sampling is not generally equal to $y_{0}$ For example, if $P_{0}=0, P_{1}=1 / 2$, $\mathrm{P}_{2}=1 / 4, \mathrm{P}_{3}=1 / 4, \mathrm{P}_{\mathrm{c}>3}=0$, and $\mathrm{N}=2$, we calculate $\mathrm{E}\left(\mathrm{a}_{1}\right)=1.75=a_{1}$, $\mathrm{E}\left(\mathrm{Nm}_{2} /(\mathrm{N}-1)\right)=0.689=\mu_{2}$, but $\mathrm{E}(\mathrm{Y}+1)=0.358 \neq \mathrm{y}+1=0.392$. In this simple case and, it will be shown, in the pertinent case of reactor fluctuation data 
the statistic $1+Y$ is a biased estimate of the parameter $1+y_{0}$ However, there are compelling reasons. for estimating $1+y$ from just this statistic。 For these reasons,.., which are outlined below, we are not concerned.with deriving a. statistịc for unbiased, efficient estimation of $1+y$, but instead we ask, "Is the magnitude of the bias negligible compared wi th the uncertainty in $1+y$ resulting from sampling. errors?" In this study, then, we shall consider the bias $\mathrm{y}-\mathrm{E}(\mathrm{Y})$ when, as in actual experiments, $\alpha_{1}$ and/or $N$ can be large or small. The standard deviation of $\mathrm{Y}$ is also treated as an estimate of: the sampling error of the y-estimate. The problem is discussed theoretically in Sec. II. The results of Sec. II are applied lu. Bec. III to data nhlinined in reactor measurements similar to those described in Ref。1。 The results are summarized in Sec.IV.

The desirability of estimating the rather awkward parameter $\dot{y}$ from small samples arises in the following manner。 In a nearly critical reaclur the ncu . tron level is subject to a slow drift as a result of changing neutron source s.trength and changing multiplication factor. The consequent drift in time of $a_{1}$ is superposed on the desired fluctuations of $C$, and a calculated sample statistic contains contributions from each of the superposed components. On thooretical grounds $\frac{(1,2)}{2}$ it is expected that $y$ is nearly unaffected by the drift because $\mu_{2}$ drifts with $a_{1}$. Hence, the contribution of the drift component can be minimized by dividing the data into blocks of adjacent time-intervals so that the drift in.. $\alpha_{1}$. relative to the average value of $\alpha_{1}$ is small In ticll block. $\Lambda n$ estimater of. $y$ is formed from the data in each block, and these estimates of $y$ are averaged to yield an overall estimate of $y$ which is nearly free of the drift component. A small. contribution of the drift to $\mathrm{y}$ can be estimated as constant $\mathrm{x}\left[\Delta \alpha_{1}\right] 2 / \bar{a}_{1}$, where $\Delta a_{1}$ is the estimated drift of $a_{1}$ in a block, $\bar{u}_{1}$ is the average value of $a_{1}$ in the block, and the constant is, e.go, $1 / 12$ for a drift of $a_{1}$ linear in time or $1 / 4$ for an exponential drift. This approximate drift correction is useful only $--2-$ 
when the drift contribution is very small. In many cases the drift contribution

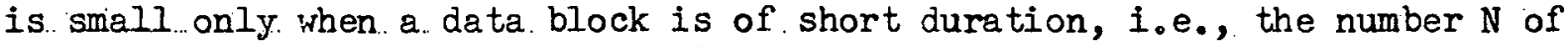
sampled counts in a block is small. The presence of drift compels us to estimate. the parameter $1+y$ rather than the usual moments $\alpha_{1}$ and $\mu_{2}$, and it can be inferred.:from the results of Sec.-II-C below that a statistic representing an unbiased..estimate of. $I+\mathrm{y}$ would be very cumbersome indeed. The biased statistic. I $+\mathrm{Y}$ is easy to compute, and it will be shown that in many cases the blas is negligible in comparison with sampling errors。

\section{ESTIMATION OF $\mathrm{y}$}

\section{A. Large Samples Drawn from a Non-Drifting Population}

It may be noted at once that asymptotically, $N \rightarrow \infty$, the sampling distribution of sample moments approaches the normal distribution for any theoretical distribution. $\mathrm{P}_{\mathrm{c}}$. This expression of the Central Limit Theorem (3) has consequences expressed in Eqs (2), (2'), and (2"). Asymptotically $(3)$

$$
\begin{array}{ll}
E\left(a_{r}\right)=a_{r} & E\left(m_{r}\right)=\mu_{r} \\
E\left(\left[a_{1}-a_{1}\right]^{2}\right)=\mu_{2} / N & E\left(\left[m_{2}-\mu_{2}\right]^{2}\right)=2 \mu_{2}^{2} / N
\end{array}
$$

Letting $Y^{\prime}$ denote $m_{2} / a_{1}-1$, we note the following theorem: $(4)$. If a function $H$ of sample moments is continuous and has continuous first and second derivatives in some neighburhood of $m_{r}=\mu_{r}, a_{r}=a_{r}$, then the variable $H$ is asymptotically normal with determined mean and variance, wich for $\mathrm{H}=\mathrm{Y}^{\prime}$ are

$$
\mathbb{T}\left(Y^{\prime}\right)=y
$$




$$
E\left(\left[Y^{\prime}-y\right]^{2}\right)=\frac{\mu_{2}^{2}\left[\mu_{2}+2 \alpha_{1}^{2}\right]}{N \alpha_{1}^{4}}=\frac{2}{N}[1+y]^{2}\left[1+\frac{1+y}{2 \alpha_{1}}\right]
$$

Thus if $\mathrm{N}$ is very. large $\mathrm{y}$ can be estimated by calculating $\mathrm{Y}^{\prime}$, and the standard deviation of $Y$ ! can be estimated from Eq (2"). Kendall has suggested (므) that samples. with $\mathrm{N} \widetilde{>} 100$ can be treated as being nearly asymptotic。

If there is a finite sampling probability that $a_{1}$ is zero, then $E(Y)$ and $E\left(Y^{1}\right)$ do not exist. This observation does not affect the results of Eqs. (2!) and (2!'), except for the triviul case $a_{1}=0$, because as $N \rightarrow \infty$ the moment distributions become less and less disperse and the singularity at $a_{1}=0$ yields.. in the limit a contribution of measure zero. (3) In the general nonasymptotic case we must assume that the sainling probabild ty that a is zero is so small that it can be treated as being zero. This is roughly. equivalent. to assuming. that $\alpha_{1}$ is large and $\mathrm{y}$ is not large. This point is discussed further. below.

\section{B. Samples: Drawn from a Population With Large Mean}

It is well known thet the Poicson distribution with mean $\alpha_{1}$, variance $\mu_{2}=a_{1}$, tends, to normality as $a_{1}$ becomes large: $(\underline{3})$ The distribution under consideration, for which $\mu_{2}=(1+y) a_{1}$, is related to, but is more disperse than, the Poisson distribution, and it is natural to assume that for large $a_{1}$ the distribution $P_{c}$ can be treated as an approximation to the normal. This assimption is not compatible with the assumption that the probability of $a_{1}=0$ is negligible unless $\mu_{2}^{1 / 2} \ll a_{1}, i_{0} e_{0}, 1+y \ll a_{1}$. If it is assumed that the distribution $P_{C}$ is approximately normal, then the variate $\xi$ defined as $\mathrm{Nm}_{2} / \mu_{2}$ is distributed approximately as $\chi^{2}$ with $N-1$ degrece of freedom for any value of $N^{(3)} i_{0} e_{0}$, 


$$
P(\xi) \mathrm{d} \xi \cong \frac{1}{\Gamma\left(\frac{\mathrm{N}-1}{2}\right)} e^{-\xi / 2}\left(\frac{\xi}{2}\right)^{\frac{\mathrm{N}-3}{2}} \cdot \frac{\mathrm{d} \xi}{2}
$$

where $P(\xi) \mathrm{d} \xi$ is the probability. that a sampled value of the variate lies between $\xi$ and $\xi+d \xi$. The variate $I+Y$ is equal to $(I+y)(N-I)^{-1} \xi a_{1} / a_{1}$, and if .we can assume that $a_{1} / a_{1}$ is distributed in a very small range about unity, then the variate $(N-I)(I+Y) /(I+y)$ is distributed approximately as $X^{2}$ with N.. - 1. degrees of freedom. The expected value of the $\chi^{2}$ distribution with $N-1$ degrees of freedom is $N-1$, while its vari ance is $2(N-1)$, so that:

$$
\begin{aligned}
& E(1+Y) \cong 1+y \\
& \ldots E\left([Y-y]^{2}\right) \cong \frac{2}{N-1}(1+y)^{2}
\end{aligned}
$$

It. may be noted that Eqs (4) are compatible wi th Eqg (2'), (2").

\section{C. . The Usual Cage}

We have discussed the case $N \rightarrow \infty, \alpha_{1} \neq 0$ and the case $\alpha_{1}>>1+y \geq 1$ under the restrictive assumption that the theoretical distributions in some sense approach the normal. Another and more general type of assumption is suggested by the requirement that $P\left(a_{1}=0\right)$ must be treated as zero so that $E(Y)$ can exist. If we assume in addition that $P\left(a_{1} \geq 2 a_{1}\right)$ can also be treated as zero. then wo can state:

$$
E(I+Y)=E\left(\frac{N}{N-1} \frac{m_{2}}{a_{1}}\left[1-\frac{a_{1}-a_{1}}{a_{1}}+\frac{\left(a_{1}-a_{1}\right)^{2}}{a_{1}^{2}}-\ldots \ldots\right]\right)
$$


The bracketed expression in Eq (5) converges for the particular values of $a_{1}$ which are possible, so the expansion is valid for the expected value. For any

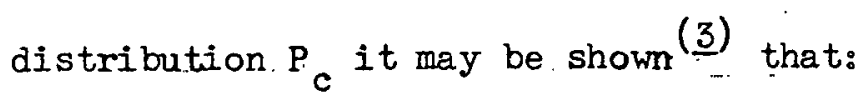

$$
\begin{aligned}
& E\left(m_{2}\right)=\frac{N-1}{N} \mu_{2} \\
& E\left(m_{2}\left[a_{1}-a_{1}\right]\right)=\frac{N-1}{N^{2}} \mu_{3} \\
& \quad: \ldots\left(m_{2}\left[a_{1}-a_{1}\right]^{2}\right)=\frac{N-1}{N^{3}} \mu_{4}+\frac{(N-1)(N-3)}{N^{3}} \mu_{2}^{2}
\end{aligned}
$$

Inserting. the expected values of $\mathrm{Eq}(6)$ into $\mathrm{Eq}(5)$ we have the expansion:

$$
E(1+Y)=(1+y)-\frac{\mu_{3}}{N a_{1}^{2}}+\frac{\mu_{4}+(N-3) \mu_{2}^{2}}{N^{2} \cdot d_{1}^{3}}-\ldots \ldots
$$

In the example presented in sec. $I, P\left(a_{1}=0\right)$ and $P\left(a_{1} \geq 2 a_{1}\right)$ are identically zerre, so the cunditiono of Eq (') are fulfliled. In this exampla $\left.\right|_{x}=0.281$; $\mu_{4}=0.1 \%$, so. Eq (7) becomoss

$$
E(1+Y)=0.392-0.046+0.014-\ldots 00
$$

Here the first three terms sum to 0.360 , which is a good approximation to the known value of $E(I+Y), 0.358$ 。

of the moment Elutistina $\mathrm{Fr}$ (6) it is necessary that the expressions $E\left(m_{2}\left[a_{1}-a_{1}\right]^{2 n}\right), n=0,1,2, \ldots \ldots$, are positive, while for distributions approximating the Poisson the expressions $E\left(m_{2}\left[a_{1}-a_{1}\right]^{2 n+1}\right)$ are also positive。 The series. Eq (7) is then alternating and convergent, and the remainder after a number of terms is less in absolute value than the cutoff term。" Thus Eq (7) suggests. the following hypothesis: If in a large number of $\mathrm{N}$-member samples 
$P\left(a_{1}=0\right)$ and $P\left(a_{1} \geq 2 a_{1}\right)$ can be treated as zero, then the relative bias of $1+Y$ as an estimate of $I+y$ is bounded by:

$$
0<\frac{(1+y)-E(1+Y)}{1+y}<\frac{\ldots \mu_{3}}{N a_{1}^{2}(1+y)}
$$

Here it has been assumed that $\mu_{3}>0$ 。 To express Eq (8) in terms of sample moments. we note that for any theoretical distribution $E\left(a_{1}\right)=a_{1}$, $E\left(m_{3} N^{2} /[N-1][N-2]\right)=\mu_{3}$, while Eq (8) predicts $E(I+Y)<1+y$. Thus Eq (8) can be. expressed as

$$
0<\frac{(1+y)-E(1+y)}{1+y}<\frac{E\left(m_{3}\right)}{E^{2}\left(a_{1}\right) E(1+Y)} \quad \frac{N}{[N-1][N-2]}
$$

D. Summary

Summarizing the results of this section we note: (a) For large samples., $N \widetilde{>} 100$, the parameter $y$. can be estimated from $Y$ or $Y^{\prime}$ with standard deviation calculable from Eq (2"); (b) For samples with large mean, $a_{1}>>1+y$, the variable. $(N-1)(1+Y) /(1+y)$ is distributed approximately as a $X^{2}$ distribution with $N-1$ degrees of freedom, while $Y$ has mean $y$ and variance approximated by...Eq (4). (s) If $P\left(a_{1}-0\right)$ and $P\left(a_{1} \geq 2 \alpha_{1}\right)$ are negligible, then the magnitude of the bias incurred in estimation of $y$ by the sample statistic $Y$ is bounded by Eqs (8) and (9):

\section{TESTS OF ESTIMATION OF Y BY Y}

The results described in the preceding Sec. II were tested by application to data obtained in a manner similar to that described in $\operatorname{Ref} 10 . \mathrm{B}^{10} \mathrm{~F}_{3}$ counters were placed at the periphery of a water moderated and reflected reactor 
WAPD-TM-157

which was fueled by slightly enriched $\mathrm{OO}_{2}$ rodso The numbers, $\mathrm{C}_{0}$ of neutroninduced counts occurring in electronically controlled time-intervals were recorded on tape...Precautions were taken during the measurements to insure minimum drift of average count rate。

The results of Sec. II can be tested by estimating the $\mathrm{y}$ parameter from data such that the drift in the mean $\alpha_{1}$ is negligible。 The statistic. $Y$ is calculated first from large samples ( $N$ large), and this value is a good estimate of $y$ o This value of $y$ is then compared to values of $y$ calculated from small samples ( $N$ small)。

The largest error in estimating $\mathrm{y}$ by the statistic $\mathrm{Y}$ is expected to occur. when both the mean $\alpha_{1}$ and the sample size $N$ are small. Accordingly, we consider first the set of data obtained as described for which the mean $a_{1}$ was least... This set of data, labeled Run 54-1, was obtained using time-intervals of $30 \mathrm{~ms}$ when the number of fuel rods in the reactor was only $92 \%$ of the number required for criticality. A histogram of the frequency.. $f_{e}$ of occurxence of $C$ counts. in the first 1000 time-intervals of Run $54-1$ is shown in Fig. I. The drift in $a_{1}$ wh.s negligible while these 1000 courls were obtaingd. Frmm this large sample $(N=1000)$. the population mowents are eulimated: $a_{1}=2.138$; $\mu_{2}=3.262: \mu_{3}=6.149: \mu_{4}=44.781$. The parameter $1+\mathrm{y}$ is estimated to be 1.526. and from Eq (2") the standard error of this determination is estimated to be U.U:iŸ. All 4700 timo intervals $\mathrm{sf}$ Run 54-1 are next divided into blocks of ten. successive time-intervals and $I+Y$ is calculated for each block $(N=.10)$ 。 The frequency of occurrence of calculated values of $1+Y$ is shown nc a histom gram in. Fig. 2. The mean of the 470 values of $I+Y 1$ s 1.384 , and the variance of the 1. 1. Y population is 0.463 . There is reason to suspect that dividing

The reactor is described in Ref 6. A more detailed description of the neutron- fluctuation measurements will be published. 
the data into blocks of ten time-intervals is questionable in this case. Noting that. none. of the means calculated for the 470 small samples are as large as twice the mean calculated from the large sample, we treat $P\left(a_{1}=0\right)$ and $P\left(a_{1} \geq 2 \alpha_{1}\right)$ as negligible, and evaluate Eq (7) from the moments estimated from the large sample. For $\mathrm{N}=10$, Eq (7) becomes:

$$
E(1+Y)=(1+y)-0.135+0.122-\ldots 000
$$

The calculated mean of the 470 small-sample values of $1+Y, 1.384$, differs from the large sample estimate of $1+y, 1.526$, by -0.142 . This discrepancy is of the sign suggested by Eq (10), and in view of sampling errors is of the order of magnitude implied by $\mathrm{Eq}(10)$. There is thus a strong implication that in this case, blocks of ten time-intervals are of inadequate size for accurate estimation of $\mathrm{y}$ by the $\mathrm{Y}$ statistic.

I.t was noted in Sec. II that the varlate $1+\mathrm{Y}$ is distributed approximately as a $\chi^{2}$ distribution (modified by the scale factor $[N-I]^{+1}[1+y]^{-1}$ ) when sample means are large and are closely clustered about the population mean. These requirements are not met by the data of Fig.2. Nevertheless the histogram of.Fig。 2 has the general appearance of, but io mure disperse than, the modified $\chi^{2}$ distribution with 9 degrees of freedom. From Eq (4) the variance of the Y distribution is estimated to be 0.345 , while the variance estimated from the histogram is 0.463 。

Figure 3 is a histogram of the frequency of occurrence of various numbers of counts in 400 time-intervals of another set of data, Run 33-3. In this case the reactor was of nearly critical size, and the duration of each time-interval was. $300 \mathrm{~ms}$. From the data of Fig。 3 the population moments are estimated. $\quad \alpha_{1}=1195 ; \mu_{2}=7909 ; \mu_{3}=12250$. The distribution is considerably 
more disperse than a Poisson distribution, for $1+Y$ is calculated to be 6.61. In this case the parameter $1+y<\alpha_{1}$, and the histogram of Fig. 3 is expected to. approximate a normal distribution. For comparison, a normal curve with the area, mean, and variance of the histogram is shown in Fig. 3 . Next, all 1900 time-intervals of Run 33-3 are divided into 190 blocks, each of ten successive time-intervals. A histogram of the frequency of occurrence of the 190 values of $1+Y$ calculated $(N=10)$ for these blocks is shown in Fig. 4. The average of the 180 val.ues of $I+Y$ is 6.60 , and the unbiased.estimate of variance of $1+Y$ calculated from the 190 values is 7.29 . - The latter value is slightly smaller than the variance 7.71 calculated. from Eq (4) on the assumption that the $1+Y$ histogram of Fig. 3 approximates a modified $\chi^{2}$ distribution with 9 degrees of freedom. The latter distribution is shown in Fig。 4 for comparison with the histogram.

Finally, the maximum relative bias of the $1+y$ estimate for blocks with $N=10$ is calculated from Eq (8) by means of the population moments estimated from the large sample. The upjer bound of the relative bias is estimated to be:

$$
\frac{\mu_{3}}{N \alpha_{1}^{2}(1+y)}=0.00017
$$

which is negligflile compared to sempling errors. It should be noted that in this case the close agreement of the estimates of $I+y$ from the large sample $(N=400)$ and from the 190 small samples $(N=10)$ is fortuitous in view of the expected sampling errors. 


\section{CONCLUSIONS}

It. has been pointed out in Sec. I that the size of the sample required for accurate estimation of $y$ by the $Y$ statistic is limited.first by an experimental: problem, the drjft in count rate. It has been shown in Secs.: II and.III that a second limitation on sample size is imposed by the bias of the $Y$ statistic in estinating $y_{0}$ The relative bias of the $Y$ statistic as an estimate of $\mathrm{y}$ is bounded by Eq (8) when, as is expected to be the usual case, $P\left(a_{1}=0\right)$ and $P\left(a_{1} \geq 2 a_{1}\right)$ are negligible and $\mu_{3}>0$. The relative bias. decreases with increasing sample size and increasing sample.mean, while the relative bias increases with increasing ratio $\mu_{3} / \mu_{2}$. The third central moment $\mu_{3}$ can be estimated from a homogeneous sample of sufficient size or from a theoretical treatment. similar to that employed.in Ref 2 to determine the parameter $1 .+y_{0}$

The sampling error of a $1+\mathrm{y}$ estimate can be estimated. from. Eq (2") for large samples or from $\mathrm{Eq}(4)$ when $1+\mathrm{y} \ll \alpha_{1}$. When these conditions are not.fulfilled Eq (4) is useful for estimation of sampling error, although the error is probably underestimated. A more accurate treatment of the sampling error of a. I $+y$ estimate would probably be impractical in view of the difficulty of estimating required higher population moments from the sample.

Neutron detecting channels employed in reactor fluctuation measurements.must be relatively noise-free, and it is convenient to test such.channels by exposing them to a completely random. (Poisson) neutron source. The $y$ parameter is estimated as described previously, and y should be greater than. zero if electronic noise is present. If the $y$ parameter is estimated by calculation of. the Y statistic a bias is introduced which can be estimated from Eq (8). "For:a. Poisson dis.tribution $\mathrm{y}=0$ and $\mu_{3}=a_{1}$, so that Eq (8) becomes: 
WAPD-TM-157

$$
0<-E(Y)<\frac{1}{N \alpha_{1}}
$$

The neutron-detectors employed in the experiments described in Sec. III were tested in this manner for noise. It was observed that when the mean. $a_{1}$ and the sample size $\mathrm{N}$ were small, a predominant number of negative values of the $\mathrm{Y}$ statistic resulted. 
1. R. R. Feynmain et al., "Dispersion of the Neutron Emission in $U^{235}$ Fission;" Nuclear Energy, Vol. 3, p. 64 (1956).

2. Fo deHoffmann, "The Science and Engineering of Nuclear Power;" Addison Wesley Press, Vol. II, (1949)。

3. H. Cramer, "Mathemat1cal Methods of Statistics," Princeton University Press (1949): :

4. Ibid., p. 366。

5. M. G.. Kendall, "The Advanced Theory of Statitics," Harper Publishing Co. (19.52)。

6. J. $R_{0}$. Brown et al, "Kinetic and Buckling Measurements on Lattices of Slightly. Enriched Uranium or $\mathrm{UO}_{2}$ Rods in Light. Water," WAPD-176 (January 1958). 


\section{FREQUENCY $f_{C}$ OF OCCURRENCE OF $C$ COUNTS IN EACH OF 1000 TIME-INTERVALS}

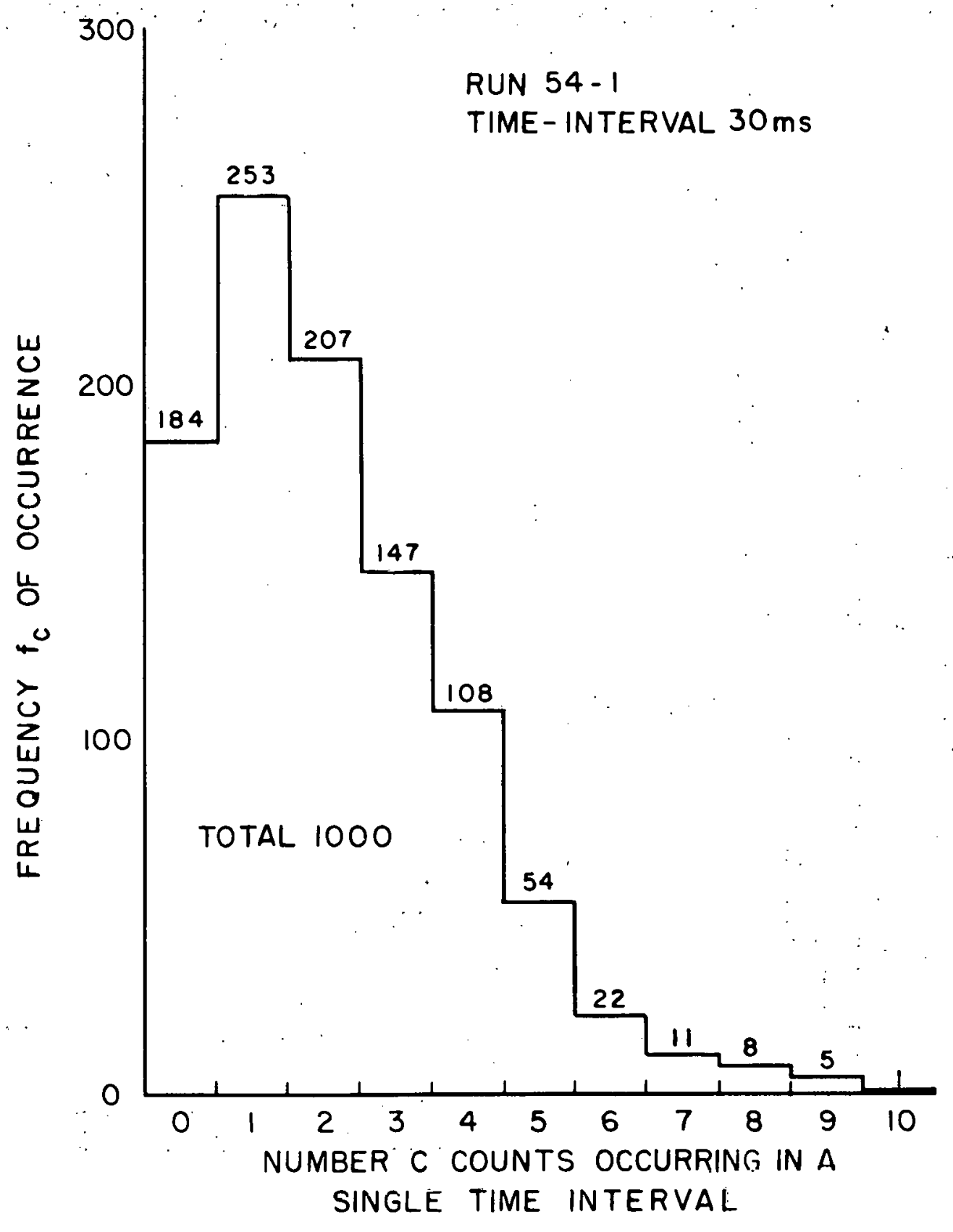

FIgure 1 
FREQUENCY OF OCCURRENCE OF I+Y VALUES CALCULATED FOR 470 BLOCKS EACH CONTAINING TEN TIME-INTERNALS

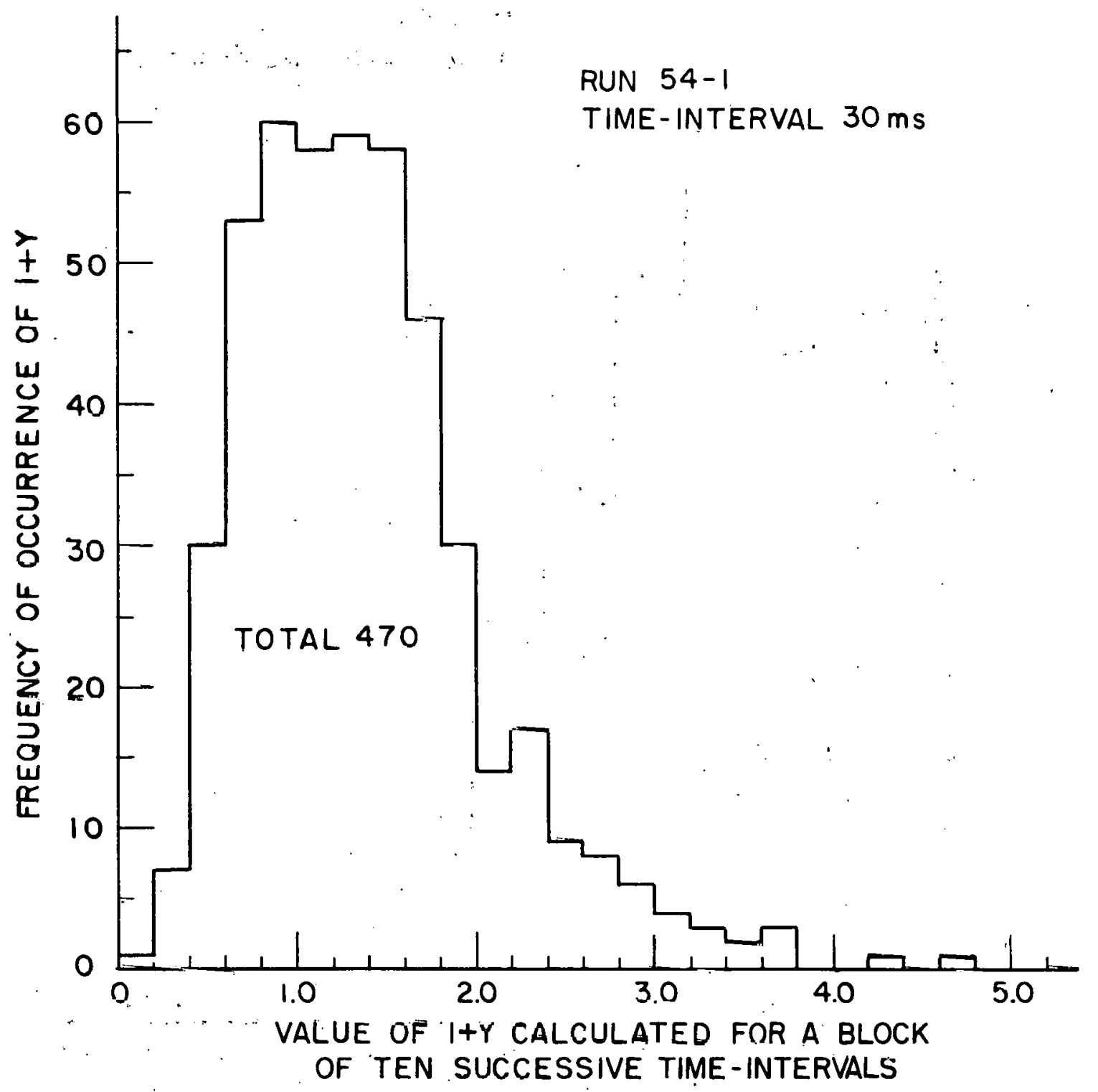




\section{FREQUENCY OF OCCURRENCE OF C COUNTS IN EACH OF 400 TIME INTERVALS}

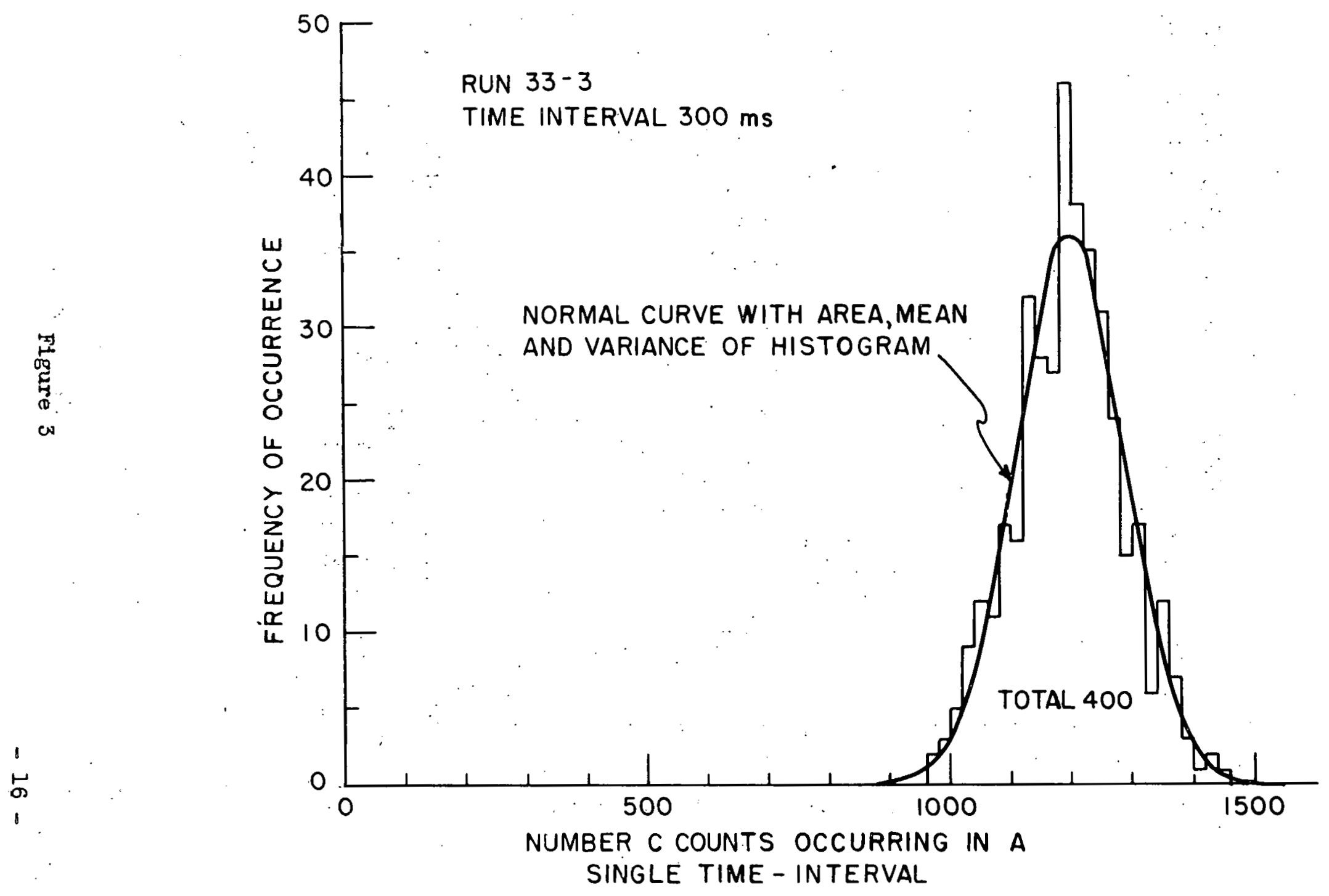


FREQUENCY OF OCCURRENCE OF I+Y VALUES CALCULATED FOR 190 BLOCKS EACH CONTAINING TEN TIME-INTERVALS

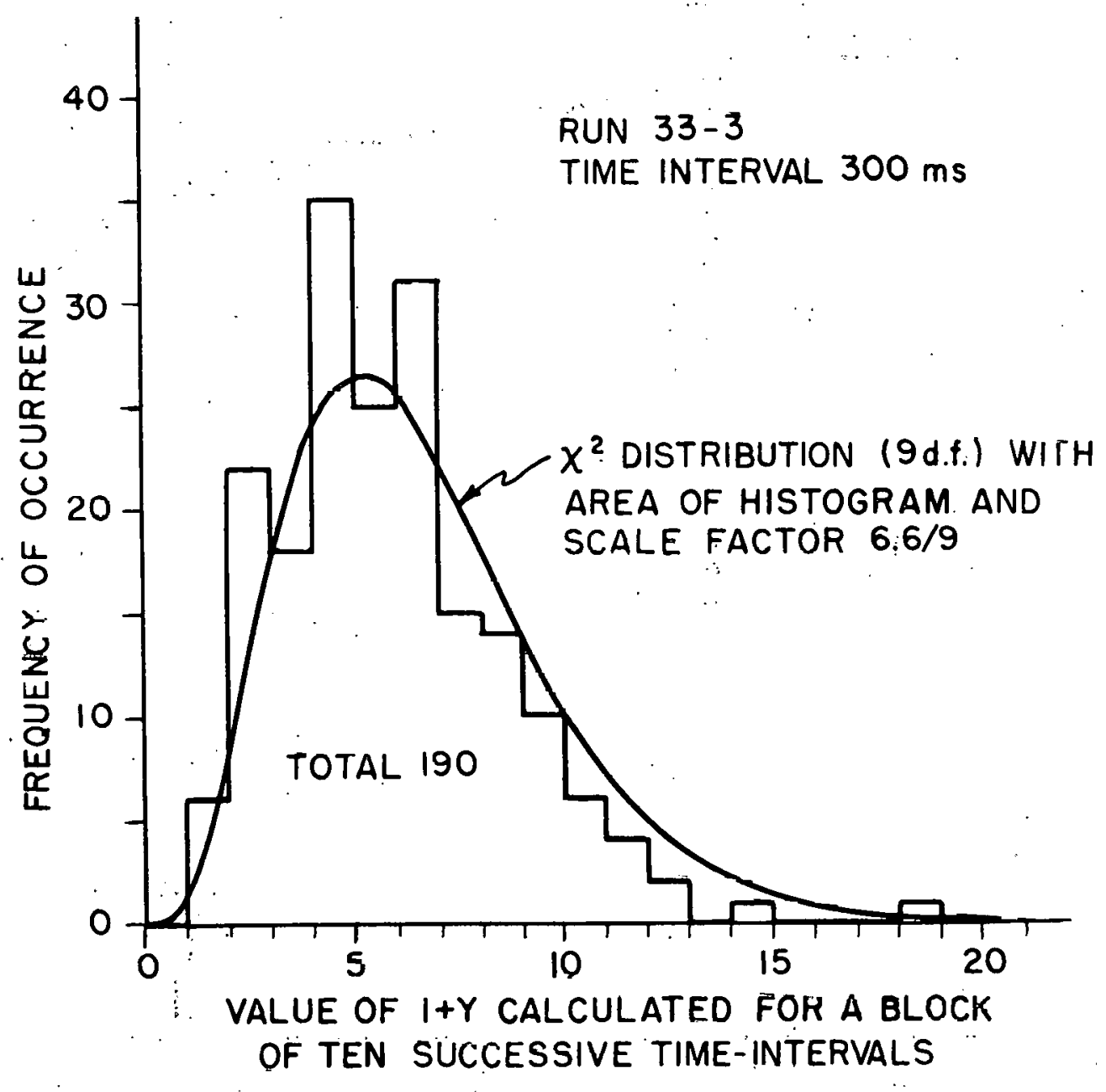

0

i 